\title{
KAN KÜLTÜRLERİN DÜŞÜK MALİYETLİ VE HIZLI ÖLÇÜLEBİLMESİ İÇİN YENİ BİR YAKLAŞIM
}

\author{
Gürsel DÜZENLI் $\dot{I}^{*}$ Oğuz KARABAY ${ }^{* *}$ \\ "Sakarya Üniversitesi, Mühendislik Fakültesi, Elektrik-Elektronik Mühendisliği Bölümü, Sakarya \\ ${ }^{* *}$ Sakarya Üniversitesi, Sağlık Bilimleri Enstitüsü, Enfeksiyon Hastalıkları AD., Sakarya \\ gursel@duzenli.net, okarabay@sakarya.edu.tr
}

(Geliş/Received:27.12.13; Kabul/Accepted:01.07.14 )

\begin{abstract}
ÖZET
Günümüzde kullanılan otomatize kan kültür ölçüm yöntemlerinde genellikle floresanlı karbondioksitin ölçümüne dayanmaktadır. Bu yöntemin en büyük dezavantajı ölçüm süresinin uzun olması ve maliyet yüksekliğidir. Bu çalışmada, tarafımızdan geliştirilen ve kan kültüründeki üremeyi, kapalı bir tüp içerisindeki basınç değişiminin monitorizasyonuyla ölçen yeni bir kan kültürü sistemi sunulmuştur. Önerdiğimiz yeni yöntem daha hızlı ve daha ekonomiktir. Yaptığımız literatür taramasında benzer bir ölçüm metoduna ilişkin hiçbir araştırmaya İngilizce yayınlanmış araştırmaya ulaşamadık. Klasik kan kültürü tüplerini kullandığımız bu yöntemde, tüplerde oluşan basıncın anlık eğim değişiminin ölçülmesine dayanan ve klasik kan kültürü ölçüm tüplerinde bakteriyel üreme sırasında oluşan gazların basınç değişimini çok hassas ölçebilen ekonomik bir cihaz tasarlandı. Yapılan ölçümlerde önerdiğimiz yöntemle, mevcut otomatize sisteme göre, pozitif raporlama için yedi kat ve negatif raporlama için 10 kat daha hızlı sonuç verilebileceği saptandı. Bu yöntem sayesinde, daha ekonomik olan standart ölçüm tüpleri kullanılarak çok daha hızlı ve ekonomik şekilde ön değerlendirmeler yapilabilecektir.
\end{abstract}

Anahtar kelimeler: Enstrümentasyon kuvvetlendiricisi, Basınç ölçümü, Kan külttürü, İnkübasyon sistem, Bakteri

\section{A NEW COST EFFECTIVE AND RAPID METHOD FOR THE MEASUREMENT OF BLOOD CULTURES}

\begin{abstract}
Current automatized blood culture measurement systems are usually based on measurement of carbon dioxide with fluorescence. Long lasting measurement period and high cost are the major disadvantages of such methods. In this study, a new blood culture measurement system that determines growth of blood cultures by monitoring pressure changes in the tube is presented. We could not find any research that investigated equivalent or similar method in English language literature. Our proposed method provides a rapid and inexpensive blood culture measurement. This method uses conventional blood culture tubes and is based on measurement of the slope of the pressure change in the tube. The new method offered here is seven times faster for positive results and 10 times faster for negative results as compared to the current automatized blood culture measurement systems. An economical device, which is able to precisely measure pressure changes of the gasses in the standard measurement tubes, has been designed. By means of this method, much faster and economic pre-assessments can be performed using standard measurement tubes that are more economic.
\end{abstract}

Keywords: Instrumentation amplifier, Pressure measurement, Blood culture, Incubation system, Bacteria.

\section{GÍRIŞ (INTRODUCTION)}

Günümüzde tıbbı teknolojide ve uygulamalardaki gelişmelere rağmen enfeksiyon hastalıkları halen en önemli ölüm ve hastalandırma nedenlerinden biridir. Toplumda ileri yaş grubunun artması, kronik hastalığı olanların yaşam sürelerinin uzaması, bağış̧ıklığı baskılayan ilaçların yaygın kullanılması ve tanı ile 
tedavi amaçlı müdahalelerde artış, özellikle hastane kaynaklı enfeksiyon riskini de arttırmıştır [1,2].

Bakteriyemi; kan dolaşımında canlı bakterinin bulunmasi; septisemi (bir mikrobun organizmaya girmesi ve kanda çoğalmasının neden olduğu genel enfeksiyon), mikro-organizmalar ve toksinlerinin dolaşıma girmesiyle oluşan sistemik hastalık tablosudur. Bakteriyemi ve sepsis, yüksek hastalandırma ve ölüm oranları ile seyreder [3]. Hasta kanında mikro-organizma saptanması (pozitiflik), sadece tanı açısından değil, hastanın tedavi ve prognozu yönünden de son derece önemlidir. Kan kültürü pozitif olan hastalarda ölüm oranı, kan kültüründe üreme olmayanlardan (negatiflik) 12 kat yüksek olarak bildirilmiştir [4]. Bu nedenle kanında bakteri bulunan hastanın erkenden tespit edilmesi ve erkenden uygun antibiyotik tedavisine başlanması hastanın hayatını kurtarabilmektedir [5]. Hastanelerde yatan hastalarda bakteriyemi siklığı \%13-24 oranındadır [4]. Hastanın durumu ağırlaştıkça bakteriyemi riski artar [6]. Yoğun bakım hastalarında bakteriyemi çok daha sıktır. Hastanın durumu ağırlaştıkça bakteriyemi şansı artmakta ve dolaşım sistemi enfeksiyonları antimikrobiyal ve destekleyici tedavilere rağmen hastalandırma ve ölümün ana nedenleri olmaya devam etmektedir. Bu nedenle kan dolaşımı enfeksiyonlarının erken tanısı ve uygun tedavi edilmesi klinik açıdan önemlidir[7, 8].

Her yıl dünyada 1,8 milyon insan sepsis nedeniyle ölmektedir. Yaklaşık olarak 1000 kişiden üçünde sepsis görülmektedir [9]. Kalp nedenli ölümlerden sonra dünyada ölümün en s1k ikinci nedeni sepsis ve bakteriyemidir [10]. Böyle bir durumda ölüm riski ise \%30-70 olarak bildirilmektedir [11]. Kan kültürleri şüpheli enfeksiyon vakalarında mikrobik nedenleri tanımladığ 1 gibi, tedavinin yönlendirilmesinde de rol oynar. $\mathrm{Bu}$ bakteriyemiye erkenden müdahale edilmezse hastanın yaşam şansı da azalmaktadır. Günümüzde çok ilaca dirençli bakterilerin neden olduğu bakteriyemi ve sepsislerin başarılı tedavisi için kanda bakterinin üretilmesi ve antibiyotik duyarlılığına göre tedavi edilmesi esastır [12]. Bugün kanında bakteri bulunan bir hastaya ilk 2 saat içinde antibiyotik başlanan hastaların \%80'ni hayatta kalırken, 12 saat sonra bașlanan hastalarda nerede ise bu oran yarıya düşmektedir [13]. Eğer sepsis halini bugünkünden daha erkenden gösterebilen sistemler tanımlanır ise hastalık daha önceden tanına bilecek ve daha erkenden tedavi başlanması sağlanabilecek ve daha fazla insanın hayatta kalması sağlanabilecektir [14].

Yukarıda sayılan nedenlerden dolayı, kan kültürü ölçüm sistemlerinin olabildiğince hızlı sonuç vermesi hayati bir öneme sahiptir [15-18]. Fakat gelişmiş ülkelerde kullanılan otomatize kan kültürü ölçüm sistemlerinin ortalama pozitiflik süresi için 5-7 günde ancak sonuç verebilmektedir. Pahalı olan bu tür otomatize sistemler kullanılmadığında kan kültürü ölçümlerin hatasız sonuçlandırılabilmesi için ortalama pozitiflik süresi için en az 8-10 gün sürebilmektedir.

Önerilen yeni kan kültürü ölçme yöntemi mevcut otomatize yöntemlere göre en az 7 kat daha hizlı sonuç verebilmektedir. Mevcut otomatize sistemlerin ilk maliyeti yüksek olmasının yanında, özel ölçüm tüplerle çalıştığından sürdürebilir maliyeti de yüksek olmaktadır. Fakat önermekte olduğumuz yeni yöntem sadece standart malzemelerle çalışabildiğinden ilk maliyeti ve sürdürebilir maliyeti en az \%30 daha ucuz olmaktadir.

$\mathrm{Bu}$ çalışmada kan kültürlerindeki üremeyi basınç temelli yöntemle ölçme esasına dayanan bu yöntemin kullanılabilirliği ve zaman yönündeki etkinliğinin araştırılması amaçlanmıştır. Makalenin geri kalan kısmı şu şekilde organize edilmiştir. 2. Bölümde önerilen yöntemin temel çalışma prensibi anlatılmıştır. 3. Bölümde önerilen yöntemin geliştirilmesinde kullanılan bakteri türleri ve ölçüm tüplerinin hazırlanışı anlatılmıştır. 4. Bölümde ise ölçüm sonuçları verilmiştir. Sonuçlar ise 5. Bölümde yer almaktadır.

\section{YÖNTEM (METHOD)}

Burada önerdiğimiz yöntemin temel çalışma prensibi; kapalı kaplar içinde bakteri üremesiyle artan basıncın ölçülmesine dayanmaktadır. Gazların basıncı, gaz moleküllerinin sürekli kabın iç yüzeyine çarpmaları sonucu oluşmakta ve

$\mathrm{P}=\mathrm{F} / \mathrm{A}$

denklemiyle formüle edilmektedir. Burada $\mathrm{P}$ basınç, $\mathrm{F}$ kuvvet ve A yüzey alanını ifade etmektedir. Kabın iç yüzeyindeki birim yüzeye, birim zamanda çarpma sayısı ne kadar fazla ise, basınç da o kadar fazladır. Gaz moleküllerinin kabın iç yüzeyindeki her noktaya çarpma sayısı eşit olduğundan, her noktadaki gaz basıncı da eşit olmaktadır. Kapalı kaptaki gazların basıncı genel olarak üç niceliğe bağlı ve ideal gaz kanunu olan

$\mathrm{P} \times \mathrm{V}=\mathrm{n} \times \mathrm{k} \times \mathrm{T}$

denklemiyle ifade edilmektedir. Burada $\mathrm{V}$ hacim, $\mathrm{n}$ molekül sayısı, k boltzman sabiti ve T sıcaklıktır.

Sicaklık ve hacim sabit ise gaz basıncı molekül sayısı ile doğru orantılıdır. Molekül sayısının artması basıncın artmasına neden olmaktadır.

Önerilen yöntem, kapalı bir kapta üreyen bakterilerin üreme döngüleri sırasında kullandıkları karbondan dolayı oluşan $\mathrm{CO}_{2}$ (karbondioksit), $\mathrm{N}$ (azot) ve diğer gazların meydana getirdiği basıncın ölçülmesine dayanmaktadır. Girişimsel olarak mutlak basınç 
ölçümü yapılarak bakteriyemini tespit edilmektedir. Mutlak basınç ölçümü vakumu referans anılarak yapılmaktadır. Mutlak basınç ölçümü yapan sensörlerde ideal vakumu oluşturmak imkansızdır. Bu nedenle, ölçümde kullanılan sensörler ideal vakuma en yakın olanı belirlenerek kullanılmıştır. Önerilen yöntem kapalı bir tüpteki oluşan basınç değerinin küçük adımlarla ve hassas ölçülerek eğim değerinin hesaplanmasına dayanmaktadır. Hesaplanan eğimlerin zamana bağlı değişimine göre bakteriyel üreme tespit edilmektedir. Basınç değerinin küçük olması nedeniyle basınç sensörün lineer ölçüm aralığının daha hassas (küçük adımlarla) ölçülebilmesi için iki tane enstrümentasyon kuvvetlendirici (En-Kuv) [19, 20] ve 24bit'lik A/D çevirici kullanıldı (Şekil 1). Bu çalışma da en yaygın bulunan üç bakteri türünün ölçülmesiyle, pozitif ve negatif numunelerin eğim değişimi formüle edilmektedir. Formüle edilen eğim değişimi referans alınarak tüm bakterilerin belirlenebilmesi için genel bir yöntem önerilmektedir.

\section{BAKTERIILER (BACTERIA)}

Kanda bakteriyemi varlığını göstermek için önceleri monofazik kan kültürleri kullanıldı [21]. Daha sonra aynı yöntem biraz daha modifiye edilerek bifazik kan kültürleri geliştirildi. Bu sistemlerde klasik agar-broth birleşimini içeren şişeler (Castaneda şişeleri) kullanıldı. Ancak bu sistemler kan kültüründe bulanıklığın gözlenerek, pasaj alınması gerekmekte idi. Gerek monofazik gerekse bifazik kan kültürlerinin ortalama pozitiflik süresi en az 8-10 günü bulmakta idi. $\mathrm{Bu}$ durum da tedavide gecikmelere yol açmaktadır. Bunun üzerine otomatize kan kültürü sistemleri geliştirildi. İlk kez 1968 de tasarlanan bu sitemlerde karbon-14-işaretli (radyokarbon, kararsız radyoaktif karbon-14 izotopu) maddenin bakteriler tarafından tüketilmeleri (üremeleri) sırasında açığa çıkan radyo-aktif karbondioksitin ölçülmesi yöntemi idi. Daha sonra 1983 de radyasyon yerine karbondioksitteki kızı̈ötesi spektrumunu ölçen sistemler geliştirildi. Dünyaca çok yaygın kullanılan bu sistemler floresanla işaretli karbonun bakteriler tarafından tüketilmeleri (üremeleri) sırasında açığa çıkan karbondioksitin neden olduğu kızılötesi spektrumunun ölçülmesi prensibine dayanmaktadır. $\mathrm{Bu}$ sistemler ortalama 10 dakikada bir tüp içindeki kızılötesi spektrumunu ölçmekte ve bu ölçüm sonucuna göre karar vermektedir [22]. Dünya'da otomatize kan kültür sistemlerinden günümüzde çok sayıda laboratuvar yararlanmaktadır. Ancak bu sistemler birçok gelişkin ülkede yaygın olarak kullanılmasına rağmen ucuz değildir [23]. Bugün daha hızlı ve daha ucuz teknoloji ile üretilebilecek alternatiflere ihtiyaç vardır [24, 25].

Birçok az gelişmiş ülkede sınırlı kaynakları nedeniyle tam otomatize kan kültürü sistemleri kullanılamamaktadır. Daha hılı ve daha ucuz bir yöntemle çalışacak bir sistem geliştirilirse bu sistem çok faydalı olabilecek açıktır. Bu çalışmada kapalı bir tüpte bakteri üremesiyle basınç değişiminin saptanmasının çok daha hızlı ve çok daha ucuz bir şekilde kanda bakteri üremesini tespit edebileceğini hipotez ettik. Bu nedenle bu çalışmada çok daha hızlı̈̈n değerlendirme yapabilen yeni bir kan kültür ölçmeyöntemi önerilmektedir. Önerilen yeni yöntem, mevcut otomatize yöntemlerine göre, çok daha hızlı ölçüm yapabilmekte ve sadece standart ekonomik ölçüm tüplerini kullanmaktadır [3, 26].

$\mathrm{Bu}$ çalışma için standart kökenler kullanıldı. Deney aşamasında Escherichia coli, Staphylococcus epidermidis (Methicillin Sensitive) ve Candida

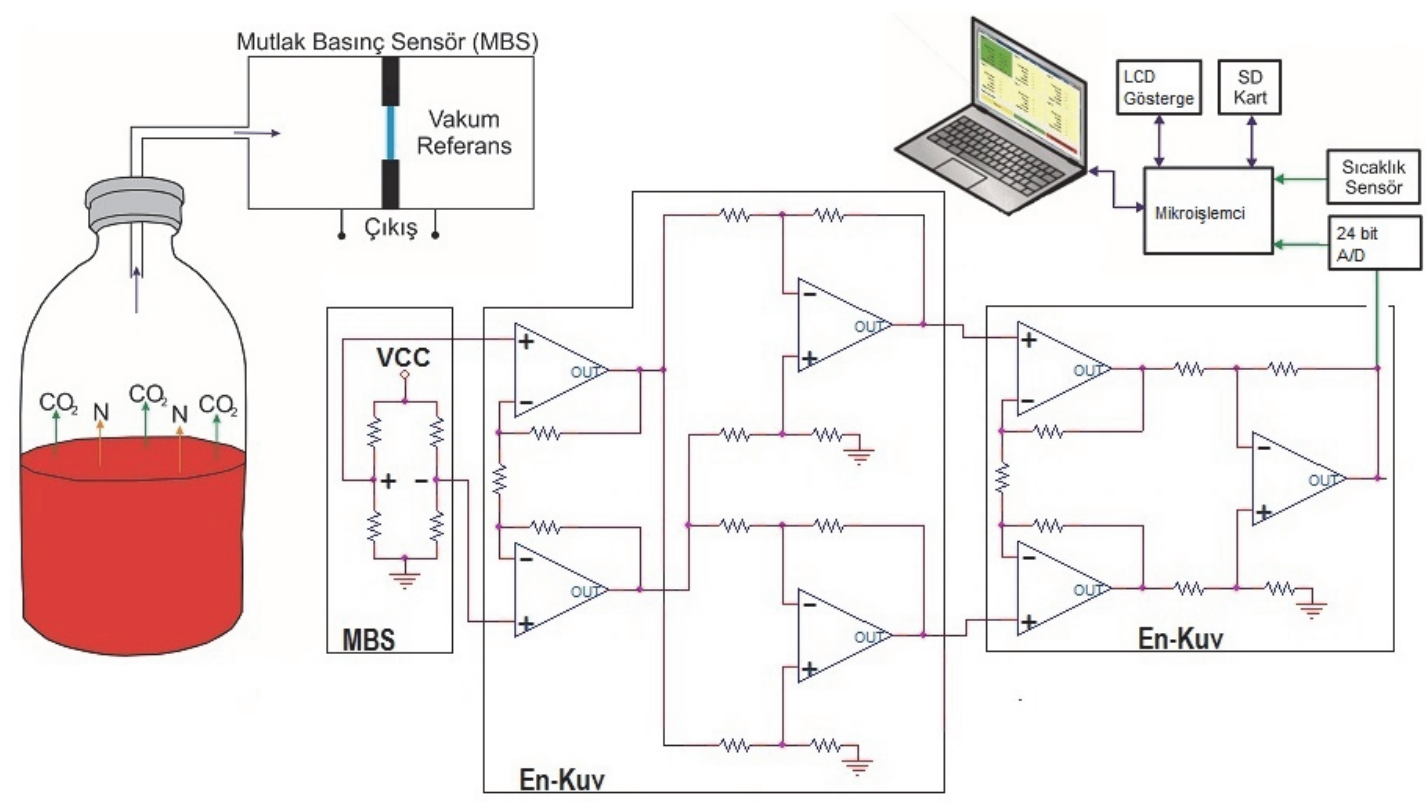

Şekil 1.Önerilen yöntemin temel ölçüm yapısı(The basic measurement structure of the proposed method) 
albicans kullanıldı. Liyofilize stok kültür halindeki bakteri ve Candida kökeni çalışma günü $\% 0,9 \mathrm{NaCl}$ solüsyonunda çözüldü. Bu solüsyondan $\% 5$ koyun kanlı agara ekim yapıldı ve $35^{\circ} \mathrm{C} 24$ saat aerop ortamda inkübe edildi. Elde edilen bakterilerden Mc Farland 1 nolu tüp bulanıklığında solüsyon elde edildi. Buradan alınan $0,1 \mathrm{ml}$ solüsyon hemokültür tüplerine doğrudan veya deneyin gereğine göre steril kan örneğine karıştırılarak ekimler yapıldı. Her bir bakteri türü için 20 adet olmak üzere toplam 60 adet ölçüm yapılarak basınç değişimlerine ait eğimler hesapland1.

\section{4. ÖLÇÜM SONUÇLARI (MEASUREMENT RESULTS)}

Önerilen sistemin ölçüm düzeneği Şekil 2'de görülmektedir. Mikroişlemci her $10^{-2}$ saniye de bir basınç ve sıcaklık değerini ölçmektedir. Her 100 ölçüm sonunda basınç değerinin eğimi ve sıcaklık değerinin ortalaması alınarak bilgisayara gönderilmektedir. Böylece her saniyede bir bilgisayara ölçüm değerleri gönderilerek toplam 24 saatlik ölçümler alınmaktadır. Ölçümler nötür, negatif ve pozitif numuneler olarak üç grup halinde yapıldı.Nötür numuneler için bakteri ve kan bulunmayanhemokültür tüpün ölçümü yapıldı. Negatif numunelerin ölçümü ise bakteri içermeyen kan yani steril kan kullanılarak yapıldı. Pozitif ölçümler için ise en yaygın olan Escherichia coli, Candida albicans ve Staphylococcus epiderimdis bakterilerini içeren kan ölçümleri yapıldı. Toplamda ise 5 farklı ölçüm numunesinin (nötür, steril, Escherichia coli, Candida albicans ve Staphylococcus epiderimdis) her biri için 20 ölçüm yapıldı. Farklı kişilere ait kan örnekleri kullanılarak tekrar edilen ölçümlerin sonuçları en fazla \%5'lik bir farkla aynı olduğundan her birisine ait tek bir ölçüm sonucu Şekil 3'de gösterilmiştir.

$\mathrm{Bu}$ şekilden görüldüğü üzere bakteri ve kan bulunmayan nötür hemokültür tüpünün ölçüm sonuçlarının yatay eğriler olarak elde edilmektedir. Steril kan yani üreme olmayan örneklerinden elde edilen ölçüm sonuçlarının hepsi azalan eğriler olarak elde edilmektedir. Buna karşılık bakteri içeren tüm ölçüm sonuçlarında ise artan bir eğri değişimi elde edilmektedir. Nötür, negatif ve pozitif ölçüm numunelerin ilk 3 saatlik ölçümleri göz önüne alındığında hepsinin eşdeğer bir değişim gösterdiği görülmektedir. $\mathrm{Bu}$ eşdeğer değişimin nedeni hemokültür tüplerin saklama sıcaklığı yani ilk sıcaklık değerinin $5^{\circ} \mathrm{C}$ olmasından kaynaklanmaktadır. Hemokültür tüplerin ölçümü sabit $37^{\circ} \mathrm{C}$ yapıldığından, ilk ölçüm anındaki sıcaklık değeri olan $5^{\circ} \mathrm{C}$ den $37^{\circ} \mathrm{C}$ gelmesine kadar tüp içindeki basınç artmaktadır. Hemokültür tüpün ölçüm sıcaklığına gelmesinden sonra ölçüm numunenin içeriğine göre sabit, azalan veya artan bir değişim göstermektedir.

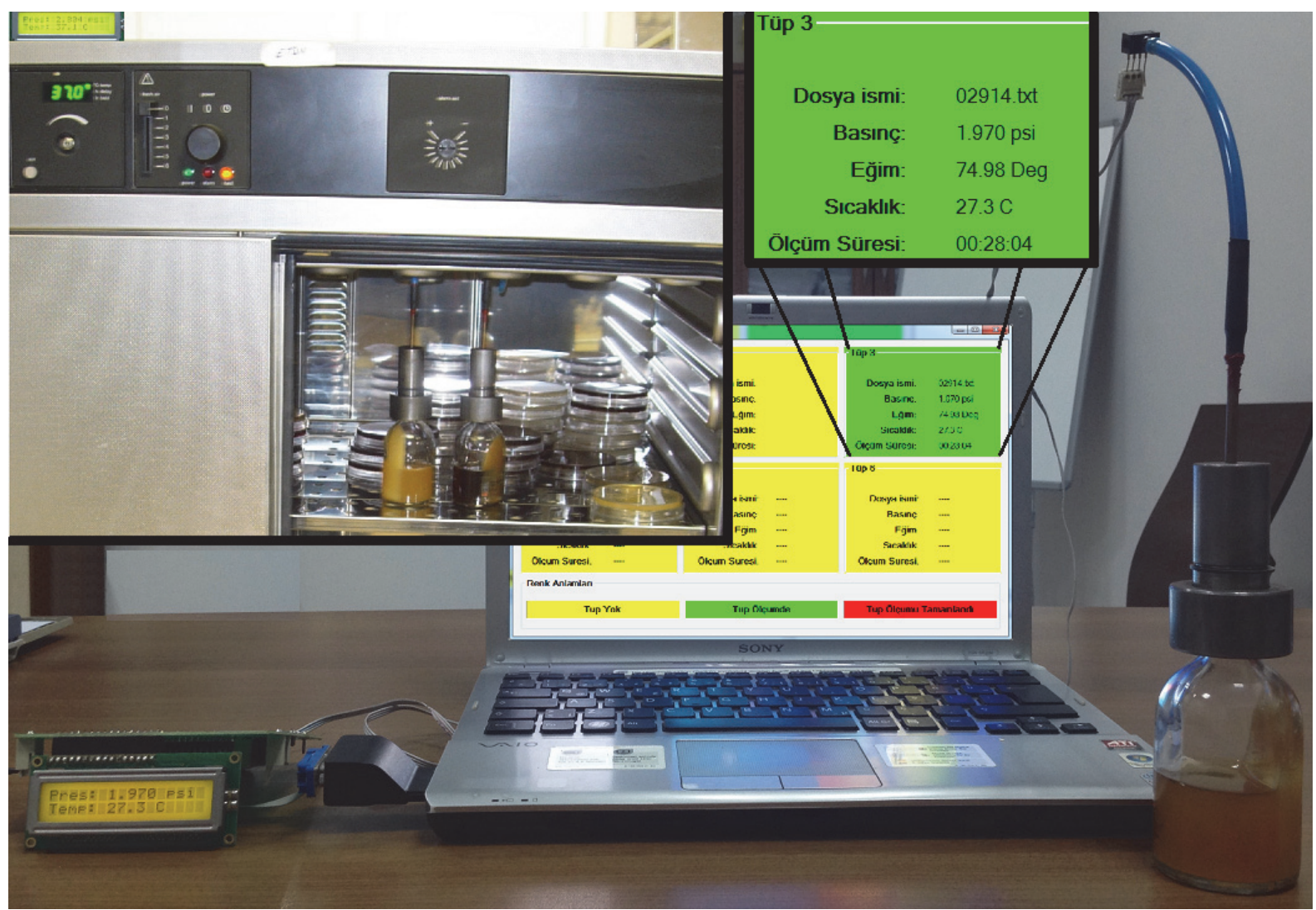

Şekil 2.Önerilen kan kültürü ölçme sistemin görüntüsü(The image of the proposed blood culture measurement system) 


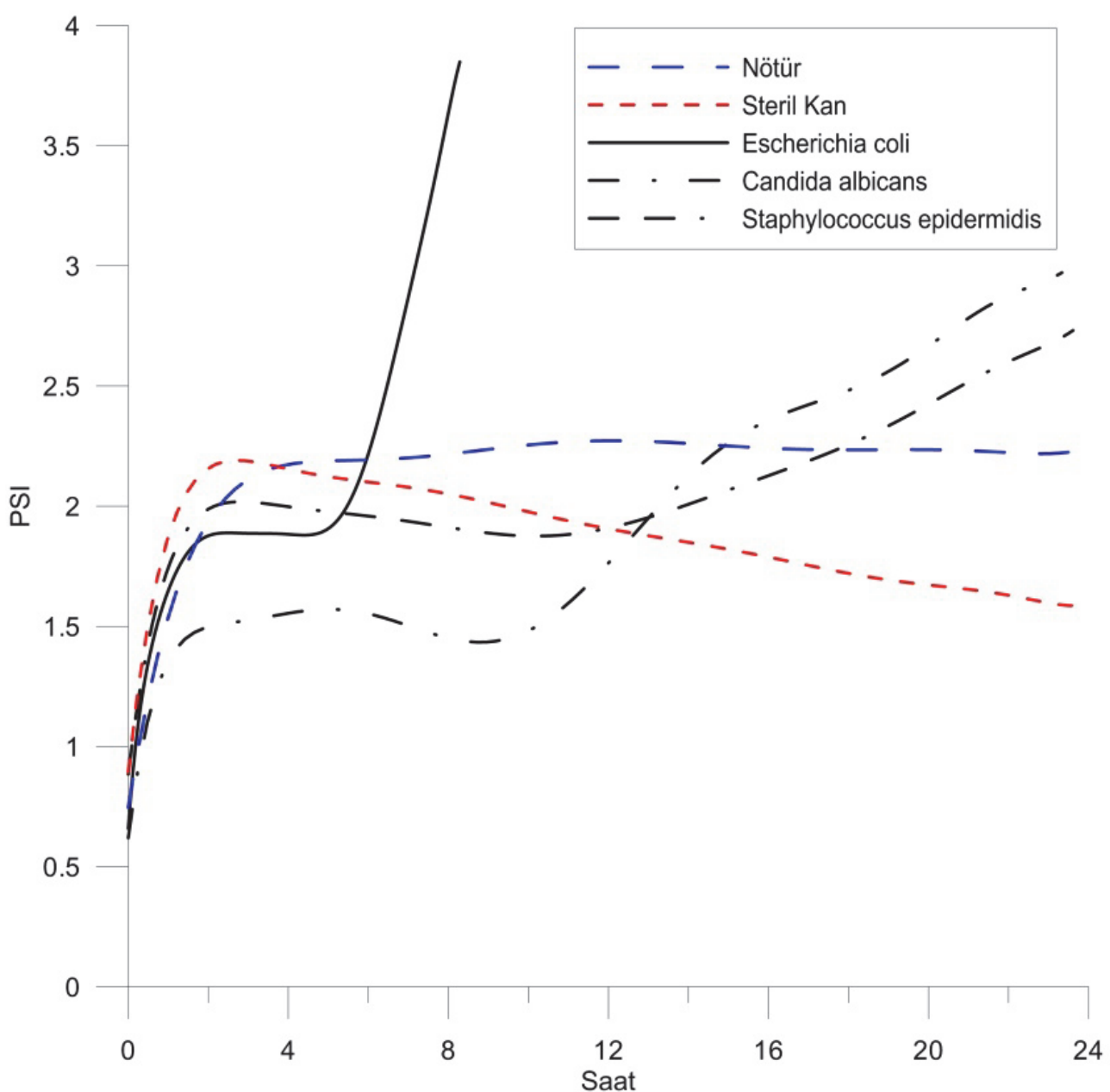

Şekil 3. Nötür, negatif ve pozitif hemokültür tüplerin basınç değişim grafiği.(The pressure variations graphic of neutral, negative and positive blood culture tube)

Nötür hemokültür tüpün ölçüm sicaklığına gelmesinden sonra sıcaklık ve molekül sayısında bir değişim olmamasından dolayı basınç sabit kalmaktadır. Buna karşılık negatif numunelere ait ölçümlerde basınç belli bir tepe değerinden sonra sabit bir eğimle azalmaktadır. Steril kan içeren tüplerin belli bir süreden sonra azalmasının nedeni, basit bir ifadeyle, kan moleküllerinin ölmesinden yani azalmasından dolayıdır. Pozitif numunelerin belli bir süreden sonra artan bir değişim göstermesinin nedeni bakterilerin hemokültür tüpün içerisinde bulunan agar-broth besiyerinden dolayı üremesi yani molekül sayısının artması ve buna bağlı $\mathrm{CO}_{2}, \mathrm{~N}$ ve diğer gazların meydana gelmesinden dolayıdır. Bunların arasında en hızlı üreyen bakteri Escherichia coli' dir. Escherichia coli'nin ayırt edilebilmesi için gereken minimum süre sadece 6 saattir. En yavaş üreyen bakteri ise Staphylococcus epiderimdis dir. Staphylococcus epiderimdis'in ayırt edilebilmesi için geçmesi gereken minimum süre 12:33 saattir. Tablo 1 'de ölçümlerin eğimleri ve eğimlerin başlangıç noktası olarak alındı eksenin değerleri verilmiştir. Bu tablodan görüldüğü üzere bakteri içeren kan kültürleri belli bir süreden sonra eğimleri yani basınçları artmaktadır. Buna karşılık bakteri içermeyen kan kültürleri belli bir süreden sonra eğimi yani basıncı azalmaktadır. Her iki durumda da molekül sayısının değişmesine bağlı olarak basınç artmakta veya azalmaktadır. Buna karşılık nötür yani hiç kan içermeyen numunelerin molekül sayılarında herhangi bir değişme olmadığından basıncı belli bir süreden sonra sabit kalmaktadır.

Tablo 1. Ölçülen numunelerin eğimleri ve eğimin başlangıç noktasına ait eksen takımın değerleri.(The slope of the measurements samples and the axis values of the starting point of the slopes.)

\begin{tabular}{|lr|r|r|}
\cline { 2 - 4 } \multicolumn{1}{c|}{} & \multirow{2}{*}{ Eğim } & \multicolumn{2}{c|}{$\begin{array}{c}\text { Ĕ̆imin başlangıç } \\
\text { noktas }\end{array}$} \\
\cline { 3 - 4 } \multicolumn{1}{c|}{} & & \multicolumn{1}{c|}{ Saat } & \multicolumn{1}{c|}{ Basınç } \\
\hline Nötür & $0^{\circ}$ & $3: 53$ & $2,17 \mathrm{psi}$ \\
\hline Steril kan & $-10,59^{\circ}$ & $2: 48$ & $2,19 \mathrm{psi}$ \\
\hline Escherichia coli & $76,73^{\circ}$ & $6: 00$ & $2,20 \mathrm{psi}$ \\
\hline Candida albicans & $44,72^{\circ}$ & $10: 36$ & $1,55 \mathrm{psi}$ \\
\hline $\begin{array}{l}\text { Staphylococcus } \\
\text { epiderimdis }\end{array}$ & $19,78^{\circ}$ & $12: 33$ & $1,94 \mathrm{psi}$ \\
\hline
\end{tabular}

Buradaki ölçüm sonuçlarında negatif (bakteri içermeyen) numunelerin pozitif (bakteri içeren) numunelerinde kolayca ayırt edilebilmektedir. Fakat unutulmamalıdır ki farklı yoğunlukta ve türdeki 
bakterilerin üreme/basınç değişimi farklı olmaktadır. Fakat yine de artan bir eğimle olmasindan dolayı önerdiğimiz sistem hatasız ve her tür bakteriyi belirleyebilmesi için eğimin değişimi dikkate alınmaktadır. Bunlar temel alınarak her tür bakteri için hızlı ve hatasız sonuç verebilmek için önerdiğimiz ölçüm yönteminin adımları aşağıdaki gibidir:

1) Ölçüm başlatıldıktan 4 saat sonra veya basınç değeri 2.5 psi geçtikten sonra eğimler hesaplanmaya başlanılmaktadır.

2) Her dakikanın sonunda anlık eğim hesaplanmaktadir.

3) Son 15 anlı eğimlerin ortalaması hesaplanmaktadir.

4) Son 15 anlık eğimin ortalama açısı en az $45^{\circ}$ olduğunda ölçülen numunenin bakteri içerdiği yani pozitif olduğu sonucu verilmektedir.

5) Son 60 anlık eğimlerin ortalamas hesaplanmaktadir.

6) Son 60 anlık eğimin ortalama açısı en az $15^{\circ}$ olduğunda ölçülen numunenin bakteri içerdiği yani pozitif olduğu sonucu verilmektedir.

7) 24 saatin sonunda eğim negatif ise numune bakteri içermediği yani negatif olduğu sonucu verilmektedir.

8) 24 saatin sonunda eğim negatif değilse belirsiz numune olduğu sonucu verilmektedir.

$\mathrm{Bu}$ adımlardaki tüm sayısal değerler deneylerde elde edilen sonuçlardan yararlanılarak belirlenmiştir. Önerdiğimiz bu yöntemin doğruluğunu gösterebilmek için farklı yaş ve cinsiyette işlemleri bitmiş ve atılmak üzere olan her türlü testleri yapılmış olan 20 gönüllüden laboratuvar ortamında alınan kan örneğinin kan kültür ölçümleri yapıldı. Önerdiğimiz sistemde ve mevcut ölçüm sisteminde bu 20 gönüllünün kan kültürleri ölçüldü ve sonuçları karşılaştırdı. Önerdiğimiz yöntemin \%100 doğrulukla olduğu gözlendi. Toplam 11 pozitif sonucu ortalama 10 saatte ve 9 negatif sonucu 24 saatte hatası olarak vermektedir (Tablo 2). Aynı sonuçları mevcut ölçüm sistemi pozitif için 3-4 günde ve negatif için 10-12 günde vermektedir. Sonuçlardan görüldüğü üzere önerilen yeni ölçüm yöntemi mevcut ölçüm sistemlerine göre çok daha hızlı ve standart ölçüm tüpleri kullanarak $\% 100$ doğrulukla sonuç vermektedir.

Tablo 2.Gerçek koşullarda kan kültürü kullanılarak yapılan ölçüm sonuçları(Measurement results of blood cultures originating from real conditions)

\begin{tabular}{|l|c|c|c|c|}
\hline \multirow{2}{*}{ Cinsiyet } & $\begin{array}{c}\text { Kişi } \\
\text { sayısı }\end{array}$ & $\begin{array}{c}\text { Yaş } \\
\text { aralığı }\end{array}$ & $\begin{array}{c}\text { Ortalama } \\
\text { ölçüm } \\
\text { süresi }\end{array}$ & Sonuç \\
\hline \multirow{2}{*}{ Erkek } & 8 & $19-75$ & $9: 41$ & Pozitif \\
\cline { 2 - 5 } & 3 & $23-37$ & $24: 00$ & Negatif \\
\hline \multirow{2}{*}{ Kadın } & 5 & $18-64$ & $10: 28$ & Pozitif \\
\cline { 2 - 5 } & 4 & $20-59$ & $24: 00$ & Negatif \\
\hline
\end{tabular}

\section{SONUÇ (CONCLUSION)}

Önerdiğimiz yeni kan kültürü ölçüm sistemi basınç değerlerini ölçerek eğimin hesaplanmasına dayanmaktadır. Hesaplanan eğim ve sıcaklık değeri ile bakteri üremesinin düzeyi belirlenmektedir. Yapılan deneylerde önerdiğimiz yöntemin mevcutölçüm sistemlerine göre aynı doğrulukta fakat çokdaha hızlı sonuç verebilmektedir. Önerdiğimiz yeni kan kültürü ölçüm yöntemi ile bakteri üremesine pozitif demek için gereken sürenin yaklaşık 10 saat ve negatif demek için gereken sürenin ise 24 saattir. Oysaki kızılötesi 1şı̆̆ın ölçülmesine dayanan yöntemlerin pozitif demek için gereken minimum sürenin 72 saat ve negatif demek için gereken sürenin ise 240 saattir. Başka bir ifadeyle, eğim değişiminin formüle edilmesine dayanan yöntemimiz mevcut yöntemlere göre pozitif için 7 kat ve negatif için 10 kat daha hızlı sonuç verebilmektedir. Tüm bu sonuçlar çok sayıda yapay ve gerçek ölçümlerle doğrulanmıştır.

Mevcut floresan işaretli karbondioksit ölçüm sistemleri yıllardan beri bütün dünyada yaygın kullanılmasından dolayı standardize hale gelmiş ve hemen her ülkede ulaşılabilir yöntemler olmuşlardır. Bugün birçok ülkede cihazlarına kolaylıkla ulaşılabilmekte ve birçok laboratuvar teknisyeni de bu cihazların kullanımı konusunda bilgi sahibidir. Oysa sunduğumuz bu teknik yenidir ve basınç esasına göre çalışmaktadır. Birçok teknisyen pahalı ve geç sonuç vermesine rağmen alışkanlıklarından ötürü klasik sistemle çalışmak istemesi doğaldır. Ancak sunduğumuz sistem hızlı ve ucuzluğu ile klasik sistemden üstündür. Sistemi kullanıcı dostu hale getirecek ara yüz yazılımlarla kolayca kullanımı yayılabilir.

Mevcut floresan işaretli karbondioksit ölçüm sistemlerinin ekipmanları özel olmasından dolayı ilk kurulum ve ölçüm tüp maliyeti yüksek olmaktadır. Buna karşılık önerdiğimiz sistemin tüm gereksinimleri piyasada çokça bulunan standart elektronik elemanlardan oluşmakta ve standart ölçüm tüplerle çalışmaktadır. Piyasada çokça bulunan standart malzemelerin kullanılması mevcut sistemlere göre çok daha ekonomik olacağı açıktır. Böyle bir sistem yaygın kullanım alanı bulabilmesi kaynakları sınırlı birçok ülke için bakteriyemi ve sepsis tanısında önemli bir yer bulabilecektir.

\section{KAYNAKLAR (REFERENCES)}

1. Sehulster, L.M., Chinn, R.Y.W., Arduino, M.J., Carpenter, J., Donlan, R., Ashford, D., Besser, R., Fields, B., McNeil, M.M., Whitney, C., Wong, S., Juranek, D. ve Cleveland, J., "Guidelines for environmental infection control in health-care facilities", Recommendations of CDC and the 
Healthcare Infection Control Practices Advisory Committee, Atlanta, A.B.D., 2003.

2. Craig, A., Umscheid, M.D., Rajender, K., Agarwal, M.D., Patrick, J. ve Brennan, M.D., "Guidelines for environmental infection control in health-care facilities", Recommendations of $\mathrm{CDC}$ and the Healthcare Infection Control Practices Advisory Committee, Atlanta, A.B.D., 2009.

3. Weinstein, M.P., "Current blood culture methods and systems: clinical concepts, technology and interpretation of results", Clinical Infectious Diseases, Cilt 23, No 1, 40-46, 1996.

4. Starnes, M.J., Brown, C.V., Morales, I.R., Hadjizacharia, P., Salim, A., Inaba, K., Rhee, P. ve Demetriades, D., "Evolving pathogens in the surgical intensive care unit: A 6-year experience", Journal of Critical Care, Cilt 23, No 4, 507-512, 2008.

5. Paul, M., Kariv, G., Goldberg, E., Raskin, M., Shaked, H., Hazzan, R., Samra, Z., Paghis, D., Bishara, J. ve Leibovici, L., "Importance of appropriate empirical antibiotic therapy for methicillin-resistant Staphylococcus aureus bacteraemia", Journal of Antimicrobial Chemotherapy, Cilt 65, No 2658-2665, 2010.

6. Diekema, D.J., Beekmann, S.E., Chapin, K.C., Morel, K.A., Munson, E. ve Doern, G.V., "Epidemiology and outcome of no-socomial and community-onset bloodstream infection", Journal of Clinical Microbiology, Cilt 41, No 8, 3655-3660, 2003.

7. Barenfanger J., Graham D.R., Kolluri L., Sangwan G., Lawhorn J., Drake C.A., Verhulst S.J., Peterson R., Moja L.B., Ertmoed M.M., Moja A.B., Shevlin D.W., Vautrain R. ve Callahan C.D., " Decreased mortality associated with prompt Gram staining of blood cultures", American Journal of Clinical Pathology. Cilt 130, No 6, 870-876, 2008.

8. Makristathis, A., Riss, S. ve Hirschl, A.M., "A novel fluorescence in situ hybridization test for rapid pathogen identification in positive blood cultures", Clinical Microbiology and Infection, Basimda, 2014.

9. Martin, G.S., Mannino, D.M., Eaton, S. ve Moss, M., "The epidemiology of sepsis in the United States from 1979 through 2000", The New England Journal Of Medicine, Cilt 348, No 16, 1546-1554, 2003.

10. Vincent, J.L., Sakr, Y., Sprung, C.L., Ranieri, V.M., Reinhart, K., Gerlach, H., Moreno, R., Carlet, J., Le Gall, J.R. ve Payen, D., "Sepsis in European intensive care units: results of the SOAP study", Critical Care Medicine, Cilt 34, No 2, 344-353, 2006.

11. Bone, R.C., Balk, R.A., Cerra, F.B., Dellinger, R.P., Fein, A.M., Knaus, W.A., Schein, R.M. ve Sibbald, W.J., "Definitions for sepsis and organ failure and guidelines for the use of innovative therapies in sepsis", Chest Journal. Cilt 101, No 6, 1644-1655, 1992.

12. Murray, P.R., Traynor, P. ve Hopson, D., "Critical assessment of blood culture techniques: analysis of recovery of obligate and facultative anaerobes, strict aerobic bacteria, and fungi in aerobic and anaerobic blood culture bottles", Journal of Clinical Microbiology, Cilt 30, No 6, 1462-1468, 1992.

13. Leea, D.H., Kimb, S.C., Baec, G., Koha, E.H., ve Kima, S., "Clinical Evaluation of BacT/Alert FA Plus and FN Plus Bottles Compared with Standard Bottles" Journal of Clinical Microbiology, Cilt 51, No 12, 4150-4155, 2013.

14. Deck, M.K., Anderson, E.S., Buckner, R.J., Colasante, G., Davis, T.E., Coull, J.M., Crystal, B., Latta, P.D., Fuchs, M., Fuller, D., Harris, W., Hazen, K., Klimas, L.L., Lindao, D., Meltzer, M.C., Morgan, M., Shepard, J., Stevens, S., Wu, F. ve Fiandaca, M.J., "Rapid detection of Enterococcus spp. direct from blood culture bottles using Enterococcus QuickFISH Method: a multicenter investigation", Diagnostic Microbiology and Infectious Disease, Cilt 78, No 4, 2014.

15. Yossepowitch, O., Dan, M., Kutchinsky, A., Gottesman, T. ve Schwartz-Harari O., "A costsaving algorithm for rapid diagnosis of Staphylococcus aureus and susceptibility to oxacillin directly from positive blood culture bottles by combined testing with BinaxNOW ${ }^{\circledR} \mathrm{S}$. aureus and Xpert MRSA/SA assay", Diagnostic Microbiology and Infectious Disease, Cilt 78, No 4, 352-355, 2014.

16. Randa, K.H. ve Delanob, J.P., "Direct identification of bacteria in positive blood cultures: comparison of two rapid methods, FilmArray and mass spectrometry", Diagnostic Microbiology and Infectious Disease, Basımda, 2014.

17. Wanga, M.C., Linc, W.H., Yand, J.J., Fange, H.Y., Kuoa, T.H., Tsenga, C.C. ve Wuf, J.J., "Early identification of microorganisms in blood culture prior to the detection of a positive signal in the BACTEC FX system using matrix-assisted laser desorption/ionization-time of flight mass spectrometry", Journal of Microbiology, Immunology and Infection, Basimda, 2013.

18. Wojewoda, C.M., Sercia, L., Navas, M., Tuohy, M., Wilson, D., Hall, G.S., Procop, G.W. ve Richter, S,S., "Evaluation of the Verigene grampositive blood culture nucleic acid test for rapid detection of bacteria and resistance determinants", Journal of Clinical Microbiology, Cilt 51, No 2072-2076, 2013.

19. Warke, N.V., Vaidya, P.P. ve Nair, J.M., "Exploring a new method for improving dynamic range of instrumentation amplifier for processing low voltage signals", IEEE 2013 International Conference on Emerging Trends in 
Communication, Control, Signal Processing \& Computing Applications, Bangalore, Hindistan, 1-4, 10-11 Eylül 2013.

20. Srivastava, N., Shadab, A. ve Shukla, G., "Yokto (10-24V) Instrumentation Amplifier" IEEE 2012 Third International Conference on Computer and Communication Technology, Allahabad, Hindistan, 116-121, 23-25 Kasim 2012.

21. Salami, M.O., Alu, S.O., Opalekunde, A.B. ve Oladipo, O.A., "Comparative Analysis between Monophasic and Biphasic Methods of Blood Culture", Journal of Biology, Agriculture and Healthcare, Cilt 2, No 4, 41-46, 2012.

22. Snyder, J.W. ve Lude, S.K., "Comparison of BacT/Alert FAN medium with Bactec NR660 plus 26A medium", Journal of Clinical Microbiology, Cilt 34, No 5, 1327-1329. 1996.

23. Shoaei, S.D., Gachkarl, L., Rafizadeh, M.,Saphadel, N. ve Phaghani, Y.A., "Comparison of Mono and Biphasic Culture Media in Isolating Bacteria from Blood and evaluation Bu-Ali Hospital Lab Quality", Journal of Paramedical Sciences, Cilt 2, No 1, 56-59, 2011.

24. Mirrett, S., Petti, C.A., Woods, C.W., Magadia, R., Weinstein, M.P. ve Reller, L.B., "Controlled clinical comparison of the BacT/ALERT FN and the standard anaerobic $\mathrm{SN}$ blood culturemedium",Journal of Clinical Microbiology, Cilt 42, No 10, 4581-4585, 2004.

25. Shanson, D.C., "Blood culture technique: current controversies", Journal of Antimicrobial Chemotherapy, Cilt 25, No Suppl C, 17-29, 1990.

26. Weckbach, L.S. ve Staneck, J.L., "Performance Characteristics of a Commercially Prepared Biphasic Blood Culture Bottle", Journal of Clinical Microbiology, Cilt 23, No 4, 700-703, 1986. 